\title{
POSIBLES BASES PARA UN FUTURO "SOCIALISMO DEMOCRATICO"
}

\author{
Roque Pozo*
}

(Reflexión propuesta para quienes aspiran un modelo de sociedadmenos desigual y más justa)

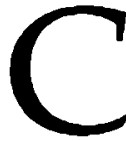

on los acontecimientos acaecidos durante estos últimos diez años, suficientemente conocidos por parte de quienes se interesan por la marcha de la sociedad a escala mundial, tenemos sobrados motivos y argumentos como para dar por concluída la fase histórica del llamado "socialismo real". La izquierda, también en el plano mundial, - con las peculiaridades propias de cada paísha quedado sorprendida, desconcertada y descolocada, tratando de reencontrar su sitio. Además, la derecha, haciendo alarde de una visión deforme de la realidad y con una debilidad radical en materia de actitudes ético-críticas, serias y rigurosas, no ha vacilado en exteriorizar a bombo y platillo que el socialismo ha sido borrado de la faz de la tierra, apresurándose a celebrar alegremente su funeral y enterramiento. $Y$, seguidamente, proclamar el triunfo incuestionable del sistema capitalista, neoliberal e individualista, equiparándolo a una especie de "parodia", puesto que no se reprime a la hora de hablar del "fin de las ideologías" y del "último hombre", liberal, por supuesto. Estas soberbias y presuntuosas afirmaciones, les descalifican intelectualmente ya que sus análisis son incompletos, apresurados, parciales, interesados y claramente tendenciosos.

- Catedrático de la Universidad de Deusto (Profesor visitante en la UCA). 
Sé que los conceptos "izquierda" y "derecha" se hallan puestos en cuestión. Yo mismo no acabo de verlos con claridad y hasta considero que, no tardando de mucho, quizás dejarán de ser utilizados. El tiempo lo dirá. De momento, sigo utilizándolos en el sentido siguiente: - la izquierda, sirve para identificar a personas y grupos que disconformes con el actual modelo de sociedad (clamorosas desigualdades entre personas, grupos, clases y países, que interpelan la sensibilidad y conciencia como seres humanos), propiciado, sostenido y ampliado por el neoliberalismo, lo denuncian y ejercen la presión de que son capaces, -hoy de forma no violenta-, para avanzar hacia un modelo de sociedad más justo y más humano, o, por lo menos, no tan deshumanizador; la derecha por el contrario, de manera torpe y cerril, se empeña en mantener a toda costa el orden social existente por temor, aunque no lo reconozcan, a perder posiciones de privilegio, de poder y de dominación; de ahí que, tampoco tenga mayor reparo en autodefinirse como conservadora. $Y$, digo esto, no ignorando que, tímidamente y no sin dificultades, está emergiendo lo que se da en llamar un centro-derecha civilizado, que se propone introducir reformas que, implícitamente, se orientan hacia una deseable transformación social. De ahí que, si no ideológicamente, al menos en la praxis, encuentren puntos de coincidencia, con el también llamado centro-izquierda.

De algún modo, la reflexión que propongo, está básicamente elaborada con la mirada puesta en ese centro-izquierda, convencido de que si es verdad - y así lo pienso- que el "socialismo real" ya es historia, ello no significa que el socialismo haya desaparecido para siempre, sino que potencialmente anida en ese centroizquierda y emergerá con fuerza bajo la forma de "socialismo democrático", al que me referiré más adelante. Añado, asimismo, que también el "capitalismo real" (neoliberal-conservador) se halla en aguda crisis y en los umbrales de un fracaso sin precedentes y de dimensión planetaria. Ahora, al no poder enfrentarse a su polo opuesto porque no existe, se ha de enfrentar —cosa nada fácil por su incapacidad para el análisis global- a sí mismo, descubriendo con horror toda la incongruencia, miseria e inhumanidad que se halla inscrita en su lógica intema.

Debo añadir, también, que el centro, al menos para mí, sigue 
siendo una realidad objetiva desdibujada e imprecisa. Creo que acierta Ralph Dahrendorf al decir: "no hay palabra en el lenguaje moderno para describir este grupo que no es grupo, esta clase que no es clase y este estrato que no es estrato". Es polémico e inaprensible por su ambigüedad, la elasticidad de sus límites, su posición intermedia no radical y menos extremosa, ni capitalista ni socialista, ni ricos ni pobres. Pero, el centro sociológicamente existe, más o menos coincidente con la clase media o medios sociales independientes, expresión esta última que utiliza Alain Touraine en sus análisis sobre la sociedad post-industrial.

Al neoliberalismo reinante en nuestros días, siempre afanoso a la hora de insistir en la defenestración del socialismo, al igual que sucede en el "Tenorio" (Zorrilla), se le puede decir... "el muerto o muertos que vos matásteis gozan de buena salud". Bien es verdad, que lo de "buena salud" no es aplicable al socialismo de nuestros días, pero sí se puede decir que sigue latente en gran parte del tejido social. Algo así como en "estado de hibernación", con posibilidad de emerger cuando lo permitan y aconsejen las condiciones objetivas que en la sociedad vayan apareciendo. Pero, sin caer en un optimismo que no viene al caso, porque lo cierto es que el "capitalismo neoliberal" tiene garantizada su permanencia para un largo tiempo, sin que ello signifique invulnerabilidad absoluta a perpetualidad. Son tantas las contradicciones económicas y sociales que su propio dinamismo ha generado que, a largo plazo, necesariamente la sociedad mundial alumbrará un nuevo sistema alternativo. No hay que olvidar que la humanidad, históricamente, se concreta en modelos de sociedad que se suceden, $y$, dentro de éllos, en sistemas socioeconómicos que, en ningún caso, -aunque sus esfuerzos por permanecer hayan sido enormes-, han sobrevivido. Se trata de una ley sociológica que inevitablemente se ha confirmado y también se registrará en lo que al sistema socioeconómico capitalista individualista se refiere. Durará todavía años, lustros, décadas, ... ¿cuántos?, ¿cuántas? No es lo que importa ahora hacer premoniciones y pronósticos. La sabiduría popular nos recuerda que "no hay mal que cien años dure". Valga su aplicación al tema que nos ocupa. 
Aproximación crítica estructural al "capitalismo real", liberal e individualista.

Toy, acientificamente, se ha optado por llamarle "neocapitalis 11 mo" o "neoliberalismo". Entiendo que esta denominación es incorrecta y no responde objetivamente a la realidad en su evolución histórico sociológica, ya que el prefijo "neo" atribuido al capitalismo como expresión práctica del liberalismo económico, es más correcto aplicarlo a la etapa en que ha estado vigente el modelo keynesiano que, dicho sea de paso, si bien se puede considerar agotado, no puede considerarse extinguido, ya que no hay modelo económico que lo sustituya. Si se observa, por otra parte, un deseo infantil, inmaduro, enfermizo, acrítico, pragmatista y pseudo intelectual, -propio de la pretendida "escuela neoliberal" - para desplazar, sin éxito, a las políticas de signo keynesiano que contribuyeron a la reconstrucción del nuevo orden liberal tan pronto concluyó la segunda guerra mundial, y, qué casualidad, tenían su antecedente más inmediato en el "New Deal" estadounidense de la década de los treinta.

La "escuela neoliberal" de nuestros días, alejándose de la realidad, vuelve a retomar un discurso propio del siglo XIX, inscrito en la misma entraña del liberalismo decimonónico. De ahí que, aún a riesgo de no ser bien entendido y peor interpretado, considero que, con todas las connotaciones peyorativas que el calificativo representa, es más ajustado a realidad hablar de "veteroliberalismo", sustentado por fuerzas tecnocráticas que no es dificil identificar. En todo caso, esta interpretación de ningún modo absolutizada por mi parte, se halla abierta a la crítica que se le quiera hacer, que gustosamente aceptaré, $y$, si lo estimo procedente, la rectificaré. O también puede ocurrir que conteste ampliando la argumentación para demostrar que mantengo mi interpretación. Este "veteroliberalismo" hoy adopta la forma de "capitalismo tecnocrático", sólidamente implantado y sostenido por empresas multinacionales-transnacionales.

Al finalizar la primera década del presente siglo WernerSombart, refiriéndose al capitalismo moderno, decía: "El capitalismo domina el mundo y hace danzar a nuestros hombres de Estado como marionetas pendientes de hilos". Que es tanto como decir que el 
Estado más que al servicio de la sociedad estaba al servicio del sistema, aunque, naturalmente, no se puede interpretar que esta dependencia haya tenido un carácter absoluto. Sí se puede afirmar, en términos relativos y de modo general, que su intervención en la realidad política, económica, social y cultural ha beneficiado más a los grupos y clases sociales privilegiadas, que a los grupos o clases sociales peor situadas. La inestabilidad social, más que combatirse con políticas sociales redistributivas, salvo en un reducido número de países, se ha afrontado - no siempre - con medidas de marcado carácter represivo.

En las postrimerías del Siglo XX (1984), Michel Beaud, dice: "El capitalismo no es una persona ni una institución. Ni quiere ni elige. Es una lógica actuando a través de un modo de producción; lógica ciega, obstinada, de acumulación". Cada cual es libre de interpretar esta concepción del capitalismo como crea conveniente. Yo creo que, cuando menos, invita a una reflexión personal seria y responsable. Esa lógica es la del beneficio a costa de lo que sea y quien sea; del interés privado, que tácitamente infravalora el interés colectivo y público; del mercado, que inconscientemente lo reduce todo a categorías mercantiles,-todo se compra y se vende-, hasta llegar al absurdo de que a la dignidad humana de las personas también se le pone precio. Esa lógica, que reduciendo la economía a puro convencionalismo, y entramado de intereses individuales, hace que su mismo sentido, -el de la economía-, quede viciado en su raiz. Invito a todos, especialmente a los economistas, a repasar la primera lección de economía, en la que se nos dice con claridad meridiana qué es y en qué consiste ésta. Esa lógica, también ha contribuído a que nuestra memoria acuse una gran fragilidad.

$\mathrm{Si}$, como antes he dicho, el fracaso del "socialismo real" es una constatación más que evidente; ahora, con el máximo de objetividad, quiero dejar también constancia de la no menos evidente crisis de legitimidad por la que atraviesa el capitalismo "neoliberal"; por lo que, quienes ciega y triunfalistamente lo proclaman como "estadio supremo" al que podia llegar la humanidad, cuando menos deberian revisar su precipitado, interesado e impertinente juicio de valor. Muy someramente, sin agotar el repertorio, señalaré algunas incongruencias que asi, sobre la marcha, se me ocurren, y que cualquiera puede constatar. 
- Económicamente: - no se da, en grado suficiente, respuesta a las necesidades realmente sentidas, al tiempo que se crean otras artificial y artificiosamente; -se dispone de datos más que suficientes para confirmar que, continuadamente, se distribuyen los recursos existentes de forma desigual entre sectores y personas (individuos, grupos, clases sociales y paises); - no se alcanza un aceptable y racional nivel de empleo de los recursos naturales, tecnológicos y humanos; - no genera las rentas o la capacidad adquisitiva necesaria para adquirir lo que es capaz de producir, dando lugar a crisis de superproducción, al tiempo que una significativa parte de la población mundial no puede satisfacer sus necesidades básicas; - la necesaria acumulación de capital para el buen funcionamiento del sistema se halla seriamente comprometida; - se trata de estimular el ahorro para invertir más, pero la inversión en tecnología avanzada - positiva en sí misma-, reduce considerablemente los puestos de trabajo;

-las economias mixtas han alcanzado un relativo equilibrio, pero a costa de dedicar menos recursos a la cobertura de necesidades colectivas o sociales; -la competitividad -objetivamente deseable- es ambivalente, ya que al tiempo que beneficia a los países productores de alta tecnología, no está ni mucho menos claro que favorezca a los paises en vias de desarrollo o subdesarrollados; -en clara demostración de irracionalidad, se busca una rentabilidad financiera a costa de los quebrantos ecológicos que todos conocemos; - los mercados financieros, fuertemente especulativos, se alejan de la economía productiva.

- Políticamente: -no se avanza hacia el ejercicio de las libertades reales porque es manifiesta la resistencia y obstaculización a la democratización de la vida económica; $-y$, como consecuenıcia, nos mantenemos en una democracia neoliberal que dista mucho de ser una democracia social y representativa; - las organizaciones sociales tales como movimientos de trabajadores, femeninos, ecológicos, indigenas, culturales, etc., como expresión de la sociedad civil, tienen reconocidos determinados derechos pero sin cauces suficientes para ejercer, con independencia de los partidos, la función política que les corresponde, enriqueciendo la actividad y vida socio-política; el capitalismo avanzado, altamente tecnologizado y tecnocratizado, entra en contradicción con la democracia 
liberal -burguesa y formal- porque obstruye el paso a una democracia participativa; - los altos indices de abstención que se registran en los comicios electorales son, en parte, prueba clara de la indiferencia y desinterés que genera el sistema democrático en gran número de países del mundo occidental; -se consiente con excesiva facilidad en la manipulación de la opinión pública a través de los medios de comunicación social, que frecuentemente se ponen al servicio de determinados grupos de intereses porque son los que disponen de recursos para pagarlos, en detrimento, claro está, de los grupos más desfavorecidos que carecen de recursos; se acentúa el "profesionalismo" político y la corrupción.

- Socinlmente: - las pequeñas y medianas empresas difícilmente resisten el impacto de las nuevas tecnologias y, en gran número, están abocadas a su desaparición o continuidad en régimen de subcontratación, siendo así que son las que más puestos de trabajo crean; -el sistema económico, desde hace ya más de veinte años viene aumentando los niveles de desempleo y se prepara para supervivir con altos índices de desempleo, muy altos en el caso de los países en vías de desarrollo; $\rightarrow$ se consolida el modelo sociedad dual y el llamado "cuarto mundo" de marginación en los paises desarrollados; - la economía del bienestar, propia de los países más desarrollados ha entrado en crisis como consecuencia de la crisis económica estructural que se registra en el plano mundial; -el corporativismo profesional se fortalece y hasta hace su aparición en la clase trabajadora; - la incorporación de tecnología avanzada desencadena un proceso de descualificación acelerada, sólo compensado con esfuerzos meritorios pero lentos de recualificación.

- Culturalmente: el consumismo irrefrenable, como modelo cultural interiorizado por la sociedad, -más, lógicamente, en los grupos privilegiados-, tiene efectos catastróficos en lo que respecta al desarrollo individual y colectivo de las personas; -la consecuencia que se sigue es la de una sociedad inmadura, poco propicia a decidir y asumir responsabilidades; el ciclo humano, reducido el hombre a objeto económico, se limita a trabajar-ganarcomprar-consumir, elevando el dinero a la categoría de valor fundamental; -al tiempo que se habla de solidaridad, en la práctica lo que se desarrolla es una nefasta "cultura de la insolidaridad y del individualismo"; -la desideologización como cultura también 
se ha instalado, siendo su expresión más concreta el pragmatismo como filosofía, y, es sobradamente sabido, que la desideologización es la peor de las ideologizaciones.

$\mathrm{Si}$ cuanto antecede, con todas las matizaciones que se quieran introducir, es algo constatable, parece obvio que es improcedente la proclamación del triunfo indiscutible del sistema neoliberal, individualista, economicista y productivista; alejado, en su praxis, de una deseable racionalidad económica, política, social y cultural. $Y$, por si esto fuera poco, los planes de ajuste económico implementados durante la última década en diversos países, son de muy dudosos efectos positivos en lo que a justicia social se refiere, cosa que no se puede obviar en ningún planteamiento económico. Que el crecimiento del producto interior bruto de un pais sea la medida que expresa su desarrollo, sin especificar en qué sectores y ramas de la actividad económica se ha producido, ni la procedencia de los capitales invertidos, ni la contribución a la formación bruta de capital fijo; ni su distribución bajo la forma de rentas entre los distintos grupos y clases sociales, ni la parte que ha de revertir a capitales extranjeros mediante la repatriación de rentas, etc., no decir nada de ésto, pues lo cierto es que no pasa de ser una forma de manipular la realidad socioeconómica, $y$, en última instancia, un modo de engañar a la sociedad.

$Y$ esto ocurre porque el "neoliberalismo" que, en su dinámica interna sigue siendo la misma lógica ciega que nunca ha dejado de ser el capitalismo liberal, cerrilmente sigue empeñado en considerar la actividad económica como variable independiente de las otras -politica, social, cultural e ideológica- que nos permiten, globalmente, tener una visión más certera de la sociedad total y real. A quienes decididamente apuestan por el "neoliberalismo" que, sin duda, cuentan con capacidad de análisis y de profundización, les recomiendo lean no sólo en su literalidad, sino entre líneas y en el transfondo, la definición de sistema socio económico, que seguidamente transcribo. Es de J. L. Sampedro, magnífico profesor de Estructura Económica, estructuralista y humanista. Dice así: "Conjunto de relaciones estructurales básicas técnicas e institucionales, - que caracterizan la organización económica total de una sociedad y determinan el sentido general de sus decisiones fundamentales, así como los cauces de su actividad". Esta definición también se 
refiere al capitalismo sea cual fuere el adjetivo calificativo que se le aplique.

Como complemento, se me ocurre añadir dos estrofas de canciones que recientemente oí en el Auditorium de la U.C.A. a un grupo de jóvenes que con gran sensibilidad social, sin alardes de erudición ni retórica política, con descaro y mucha sinceridad decían: "... un rostro arrugado, desconocido e irreconocible, llama a tu puerta, ... trae de la mano cinco niños hambrientos y descalzos; "... en esta sociedad en la que unos viven a costa de otros y se abusa del más débil". Estas estrofas no pueden pasar desapercibidas para nadie. Nos interpelan seriamente, tanto a quienes defienden el "neoliberalismo" con la razón de la fuerza como a quienes lo combatimos con la fuerza de la razón, o, por lo menos, con argumentos que consideramos razonables. $Y$, si no, que se nos haga la crítica que se crea conveniente. Sabemos escuchar y rectificar, si llega el caso. Pero se nos ha de convencer con análisis científicos, estructurales y serios.

\section{La socialdemocracia no sirve como alternativa al neoliberalismo}

uando nos referimos al "socialismo real" y al"capitalismo real
neoliberal" resulta relativamente fácil situarlos en el tiempo y en el espacio. Incluso, un sencillo análisis estructural nos permite identificarlos en su filosofía y en su praxis. Sabemos decir qué es o qué ha sido, cómo es o cómo ha sido, dónde se localiza, a qué intereses responden o han respondido y por qué, cuáles son o han sido sus objetivos económicos, políticos, sociales y culturales, y quiénes, o cuáles son o han sido los individuos, grupos, clases y países que los han impulsado y sostenido. No ocurre lo mismo con la socialdemocracia, ya que resulta dificil identificar una ideologia que no es ideologia, un sistema que no es sistema, un proyecto que no es proyecto y un modelo de sociedad que no es modelo de sociedad. Con toda clase de cautelas y matizaciones se puede hablar de una escuela de pensamiento y de una práctica económica, política y social. En todo caso muy versátil, dependiendo su implantación y escasa o relativa consolidación del área geográfica, de cada país en concreto, del nivel de desarrollo industrial y tecnológico, de la mayor o menor tolerancia y necesidad del 
sistema socioeconómico global en el que opera, del carisma, aceptación y calibre intelectual de quienes, más por razones políticas que económico-sociales, optan por alinearse a esta posición y desde ella, quiero pensar que con honestidad y legítimamente, aspiran a asumir responsabilidades políticas, aún a riesgo de derivar hacia el "profesionalismo político", del que no está libre ninguna otra opción. Así, resulta que la vacilación, indefinición y ambigüedad son "signos externos" de la socialdemocracia y de los socialdemócratas que, aunque no comparta su opción y criterios, merecen mi consideración y respeto, como todos aquéllos que, coherentes con sus personales convicciones, realizan la opción que creen oportuna.

Los origenes y trayectoria histórica de la socialdemocracia podemos encontrarlos en libros de historia del pensamiento económico y social e igualmente en publicaciones de sociología política. De ahí que, para no alargar demasiado este trabajo, no me detengo en hacer una síntesis. Sí me voy a permitir subrayar algunas apreciaciones que, segun mi leal saber y entender, vienen como anillo al dedo en esta reflexión critica que estoy realizando, sabedor de que siendo todo opinable, habrá quienes las compartan y otros que disientan. Todas las opiniones razonadas y razonablemente críticas serán bienvenidas. Entre todos, vamos haciendo camino. De momento, me aventuro a subrayar los siguientes aspectos en relación con la socialdemocracia:

- Su acción política opera o funciona en clave de puro pragmatismo político que, al no disponer de ideologia propia, puede bascular indistintamente hacia un socialismo moderado o hacia un neoliberalismo no salvaje. Todo dependerá del contexto socioeconómico y sociopolítico, del juego de presiones nacionales e internacionales y de las aspiraciones personales de quienes, con la legitimidad que las urnas les otorgan, estén dispuestos a postular y defender sus ideas y su práctica política en los estrechos márgenes que otros posicionamientos le puedan dejar.

- En el ámbito europeo la socialdemocracia ha ido alejándose progresivamente del marxismo apostando por una denominada economia social de mercado, en la que el adjetivo social no está 
muy claro si responde a la realidad o es simple concesión verbal. No obstante, durante una bastante larga etapa de crecimiento económico, se ha situado en la lógica de la economía o sociedad del bienestar, -también, según algunos "Estado del Bienestar" o "Estado Social"-, propugnando políticas de rentas y poiíticas fiscales correctoras de desigualdades y redistribuidoras de recursos, así como políticas de inversiones y de empleo que ampliaban la población efectivamente activa y reducian a niveles tolerables los índices de desempleo.

- Los puntos positivos a que me refiero en el párrafo anterior, se pueden constatar en una parte de los veinticuatro paises integrantes de la O.C.D.E., es decir, aquéllos que han alcanzado un alto y medio nivel de desarrollo industrial. No así en los paises subdesarrollados o en vías de desarrollo cuyo crecimiento ha sido escaso o, salvo excepciones, negativo, en la década de los ochenta. La crisis económica mundial que se registra desde hace más de veinte años, ha recortado sensiblemente las posibilidades de la socialdemocracia, hasta en los países más desarrollados.

- El "neoliberalismo" también ha influído negativamente en la socialdemocracia, desnaturalizándola, o, mejor, oponiendo gran resistencia a sus pretensiones de transformar en lo posible el modelo de sociedad actual, cimentado sobre las enormes desigualdades a que antes me he referido. Hasta el punto de que, para implementar políticas de ajuste económico, ha sido instrumentalizada y utilizada como medio para frenar la presión social proveniente de organizaciones obreras. La única posibilidad que le ha quedado a la socialdemocracia es dirigirse cada vez más espaciadamente y con menos contundencia al Estado y a otras Administraciones Públicas, para hacer de portavoz de algunas de las quejas y reivindicaciones de quienes se hallan peor situados en la sociedad. Pero siempre, evitando tensar los problemas y radicalizar los conflictos.

- Y todo ésto ha sucedido así, porque la socialdemocracia, desde sus comienzos, lejos de oponerse al sistema capitalista todavía decimonónico, se mostraba como fuerza política de sustitución, en cualquier caso dentro del sistema. Es decir, que en ningún momento ha orientado sus pasos hacia un sistema socio-econó- 
mico distinto. En tal sentido, conviene constatar que cuando el modelo keynesiano, soporte temporal de la socialdemocracia, se considera agotado, ésta ha carecido de fuerza social y teórica para racionalizar la "contrareforma" del liberalismo mediante mecanismos capaces de socializar mínimamente el libre mercado que, hoy, - para nadie es una novedad-, se ha convertido en una especie de "selva" en la que, como muchos dicen, la competencia se devora a sí misma, ya que es la "ley del más fuerte" la que se impone.

- A la socialdemocracia le ha ocurrido algo que, con matices, nos ha sucedido a todos. Hemos confundido nivel de vida, medido en base a indicadores de consumo, con calidad de vida que hace referencia a valores que no son objeto de compraventa en el mercado, sino que se hallan inscritos en lo más radical de la persona que es su conciencia. De tal manera, que tampoco se ha hecho presente, de forma clara y evidente, en la lucha por reencontrar un camino de humanización. Así se explica que su presencia haya sido prácticamente nula en la lucha de los países subdesarrollados para salir de su situación, proponiendo políticas económicas, comerciales y financieras, no tan lesivas para sus intereses como las que se han implementado. Sus propuestas, cuando han tenido lugar, no han tenido una verdadera proyección internacional.

- En definitiva, la socialdemocracia no ha sido capaz de llevar a efecto políticas propias y autónomas, ya que desde su interior y desde el exterior, ha sido perfectamente dirigida y controlada por el capitalismo liberal y en la actualidad por el "neoliberalismo". La misma naturaleza de la socialdemocracia ha hecho que el proceso seguido sea éste y no otro, porque en el fondo ha estado siempre impregnada, según las circunstancias, de una importante dosis de individualismo; filosofia, dicho sea de paso, de la que todos, -con diferencias no fácil de apreciar-, somos tributarios, aunque unos lo disimulen mejor o peor que otros. $Y$, ya se sabe, los planteamientos individualistas terminan en. "movimientos nacionalistas y patrióticos". Eso de que el mundo se ha convertido en una "aldea global" y de que se ha "internacionalizado", no entra fácilmente en la mentalidad, actitudes y comportamientos de socialdemócratas-individualistas-na- 
cionalistas-patrióticos.

De un artículo de opinión en la prensa (junio 1993),suscrito por el profesor y analista político Maurice Duverger, persona lúcida y ponderada, reconocida internacionalmente, extraigo algunos párrafos que no pierden valor y sentido por sacarse fuera de contexto y facilitan una mejor comprensión de lo que hasta el momento he expuesto en relación con la socialdemocracia. son los siguientes:

- "... Algunos electores socialistas, tanto en España como en Francia, están decepcionados por el hecho de que su partido haya resultado más gestor que innovador a la hora de ejercer el poder. Esto explica la supervivencia de organizaciones comunistas o paracomunistas en ambos paises". "Todos los partidos socialistas, más doctrinarios en la oposición, han tenido que volverse más realistas, $\longrightarrow$ lo que es igual socialdemocratizarse-, al acceder al gobierno.

- "... Todos se van haciendo gestores poco a poco, una vez que han logrado corregir los mecanismos de la competencia y del mercado mediante la seguridad social que los hace menos injustos, mediante la política coyuntural que atenúa sus desviaciones, mediante la formación de los trabajadores y la ayuda a la investigación que incrementa su dinamismo".

- "... Al evolucionar en este sentido, priva a los Estados de los medios de poder público desarrollados por el socialismo democrático, sin ejercerlos en su lugar. Favorece así la competencia social desleal, al brindar al sureste de Asia la posibilidadad de exportar a nuestro continente productos a bajo precio, gracias a la ausencia de seguridad social y a la exigüidad de los salarios".

- "... Empieza a ser urgente que los países de los Estados miembros de la C. E., elaboren un proyecto socialista concebido en el marco de la comunidad, en función de una mundialización del capitalismo que vuelve totalmente obsoletas las perspectivas elaboradas por Marx a partir del capitalismo de 1860 . Los ciudadanos empiezan a adquirir conciencia de este problema alejándose de la moda neoliberal de los años ochenta". 
A nadie se le puede ocultar que lo dicho en este epígrafe, expresamente dedicado a la socialdemocracia, es absolutamente discutible y, además, no lo dice todo. Tampoco lo he pretendido. Se trata, sencillamente, de suscitar una reflexión y una polémica que ayude a proyectar un poco de luz en el largo camino que aún hemos de transitar hasta alcanzar los umbrales de un modelo de sociedad más acorde con lo que todo ser humano necesita para crecer y desarrollarse como lo que somos, personas. Oskar Lafontaine, intelectual, luchador infatigable y humanista, decía: "Vivimos en un tiempo de grandes amenazas y de grandes posibilidades. Cuando se vive en esta situación no tenemos que desechar las utopías de la izquierda, sino que hay que conservarlas para saber cuál es el rumbo"... "En los últimos años hemos aprendido que la cifra del crecimiento del producto nacional bruto no dice nada en absoluto, sino que los resultados económicos tienen que ser completados con los del campo ecológico y social".

\section{Un lugar para la esperanza: el "socialismo democrático"}

Si el "socialismo real" o marxismo-leninismo ha fracasado,y con ca; si el "capitalismo neoliberal" atrincherado en posiciones irreductibles, fomenta el desequilibrio económico y social en el plano nacional e internacional, acrecienta las tensiones y nos sumerge en un individualismo sutil y subliminalmente interiorizado que nos hace insolidarios; si la "socialdemocracia" por su ambigüedad e indefinición carece de consistencia ideológica y programática y es incapaz de formalizar propuestas que, parcial y lentamente modifiquen la actual estructura social radicalmente injusta, -entonces, qué ¿ ¿La sociedad, a escala planetaria, está inevitablemente condenada a no avanzar por caminos de solidaridad, a enfrentamientos cruentos, a la degradación y desintegración social y a que de forma inmisericorde nos destrocemos unos a otros, sean individuos, grupos, clases o paises?, ¿es que las perspectivas forzosamente han de ser catastróficas para la humanidad?, ¿es que volverán a hacerse presentes trasnochados milenarismos, propicios a la aparición de profetas de calamidades?

Sinceramente, creo que, sin confundir deseos con realidad,el ser humano, -individual y colectivamente-, sigue conservando, la- 
tente y manifiestamente, algo que en él es entitativo y no podrá desaparecer; su consciencia, su sociabilidad, sus aspiraciones de solidaridad, su esfuerzo por construir paz y democracia, la libertad relativa inherente a toda persona, su disconformidad con los abismales desigualdades que se constatan y que degradan la condición humana, su capacidad de aprender de los errores cometidos y rectificar, su búsqueda incesante e imparable para hallar caminos que conducen a la verdad individual y colectiva, su afán por actuar organizadamente junto con los otros aunque sean discrepantes, porque en la mente y el corazón humano se halla inscrito el convencimiento de que sólos, aisladamente y enfrentados, nos podemos convertir en fieras que se desgarran y aniquilan. Hay capacidad reflexiva y sabiduría en los colectivos humanos. En todos, también en los más populares, pobres y oprimidos.

Todo ésto, nos permite afirmar que hay un lugar para la esperanza, actitud que estimula la creatividad y abre las puertas de un futuro más prometedor. Esta esperanza, expresada en términos económicos, políticos, sociales y culturales, para quien suscribe este trabajo tiene un nombre. Se llama "socialismo democrático", no entendido como futuro del actual socialismo sino como el socialismo del futuro, capaz de arrastrar tras de sí, no como ensoñación, sino como utopía real y positiva, a distintos grupos que hoy integran políticamente la "izquierda" y a otros movimientos sociales que, a pesar de su importancia y persistencia, aún no han sido tomados en consideración en lo que realmente se proponen y representan.

Además, tengo bien presente una expresión-reflexión netamente histórico-sociológica, que no por repetida ha perdido sentido, sino todo lo contrario, sigue siendo vigente, - "el presente configura el futuro". Y si esto es cierto, -yo creo que lo es-, en el momento actual de la sociedad, -nacional y mundial- se hallan los elementos y factores necesarios para hacer posible esa utopia que ya somos muchos en denominar "socialismo democrático". Si hace unos instantes, con los argumentos expuestos, he descalificado al "socialismo real", al "capitalismo neoliberal" y a la "socialdemocracia", en coherencia con lo que ahora acabo de señalar, tengo que añadir que la descalificación se refiere al modelo de sociedad que propugnan $y$, en ningún caso, quiere ser absoluta. Porque, 
precisamente, en cada una de esas experiencias, - que tanto han influido y siguen influyendo a nivel mundial-, hay aspectos a los que no se les pueden negar validez objetiva, y son éstos valores positivos los que hemos de tener en cuenta para, con creatividad e imaginación, sentar las bases de un futuro "socialismo democrático" $^{\prime \prime}$ que, por tener como referente la libertad en solidaridad será humanizador, teniendo siempre presentes a los grupos y clases más débiles y peor tratados por la sociedad, es decir, que a alcanzar el máximo posible de justicia social nadie se puede negar, a no ser que posea una mente abstrusa, obtusa y confusa, que, todo hay que decirlo, se trata de "especímenes" que por desgracia abundar.

Seguidamente, -sin pretender ofrecer un modelo de sistema socioeconómico completo y acabado-, cosa que, por vana pretensión no vendría al caso, me limitaré, eso sí, a poner de relieve los elementos más sustantivos que a mi juicio pueden y deben constituir los cimientos - la base - de ese edificio, aún en anteproyecto, que es o puede llegar a ser el deseable "socialismo democrático". Los detallo a continuación, seguidos de un breve comentario.

- Propiedad social. Referida a los medios de producción que ofrecen la posibilidad de multiplicar la capacidad del trabajo humano organizado. Esta forma social de entender la propiedad, significa que no necesariamente son incompatibles la propiedad pública y la propiedad privada, sino que al revés, pueden estar sustentadas en los mismos criterios de eficacia y eficiencia. No toda propiedad pública "per se" es ineficaz e ineficiente si de modo real y efectivo se halla controlada social y políticamente y se arbitran los cauces e instrumentos para tal fin. La propiedad privada seguirá ocupando un lugar preponderante como estimulo y acicate para la iniciativa privada de la que no se puede ni se debe prescirdir. También he de recordar, -los testimonios son abundantes-, que el simple hecho de la propiedad privada no es garantía de eficacia y eficiencia, en lo que se refiere a producción, organización, gestión y resultados. Se trataría de buscar un equilibrio entre propiedad pública y propiedad privada, no ignorando que la propiedad, en sí misma, es fuente de poder, y, por consiguiente, afecta a la soberanía popular que, si bien es proclamada reiteradamente, en ningún momento ni en ningún país, se ha logrado en un nivel suficiente y aceptable, como para decir que se 
trata de algo más que de retórica con fines electoralistas. La propiedad, bajo la forma de empresas cooperativas no es nada desdeñable, ya que pasan de un millón las que hay en la actualidad. Tampoco se debe prescindir de la propiedad sindical, a pesar de que algunas de sus experiencias hayan resultado un fracaso y hasta se hayan observado prácticas fraudulentas. Del fraude no se halla exenta la empresa privada $y$, a pesar de ello, sin la menor duda, me pronuncio por la continuidad de su existencia en la mayor proporción posible respecto al total de la propiedad de los medios de producción. Sí considero un retroceso no deseable defender a ultranza la propiedad "individualista" y la propiedad "estatalísta". Equilibrio en la distribución social de la propiedad de los medios de producción es signo de salud económica y social y se sitúa en la misma entraña de los objetivos de la economía política.

- Planificación democrática de la producción. Punto éste sumamente discutible y controvertido. Más aún, después del rotundo fracaso de la planificación soviética y países de su órbita. Es por ello, por lo que muchos, en particular neoliberales-, rechazan por inadecuada, inservible y demoníaca toda planificación, ya que ésta, en sí misma es maligna y perversa. Claro que, son pocos los que ingnoran que este rechazo frontal, responde a determinados y muy concretos intereses económicos y políticos que, en el fondo, tienen que ver con el poder estatal y supraestatal. No se oponen, naturalmente, a la planificación estratégica de la producción propia de las grandes empresas, como algo inevitablemente necesario, cosa que yo también acepto, si bien no acríticamente.

No todo lo que se produce, estratégicamente hablando, responde a necesidades y urgencias económicas, sino a un beneficio privado. Cuántas veces nos preguntamos, ¿para qué sirven realmente muchas de las cosas que se producen y se venden con el apoyo de una publicidad y propaganda para captar el interés de incautos e incultos? Que no se me interprete mal, no estoy descalificando toda la publicidad y propaganda, pues también la hay buena y pertinente. Sí, como es de esperar, me interesa destacar la conveniencia y necesidad de una planificación democrática de la producción.

Y si es democrática la planificación, a priori no tiene por qué 
ser descartada. Es más, si así sucediese, habría que dudar de las actitudes y conductas democráticas de quienes opusieran resistencia y rechazo, ya que, lo que defienden es la libertad absoluta de empresa para la iniciativa privada y, por tanto, también intereses privados cuya legitimidad no pongo en cuestión, aunque en ocasiones sea discutible su licitud. En el marco de una planificación democrática y democratizadora, cabe perfectamente la planificación estratégica de las empresas como práctica conveniente y deseable. En los organismos de planificación democrática creados al efecto, entrarían a formar parte representación de la propiedad e iniciativa privadas, pública, cooperativa y sindical y las decisiones acerca de qué producir, cuánto producir, cómo producir, quién producir, para quién producir y cuándo producir se tomarian por consenso teniendo en consideración todas las variables que entran en tan complejos planteamientos.

En todo caso, ateniéndose a criterios de necesidades reales, eficacia económica, eficiencia práctica, racional vertebración del mercado, consecución del legítimo beneficio y respuesta suficiente a la necesidad ineludible de acumulación de capital instrumental y tecnológico. Quienes hayan participado en la toma de decisiones, en los momentos previamente fijados, también participarán en el control de los planes consensuados, para ver si los objetivos se cumplen y en qué medida; e, igualmente, tomar nota de las desviaciones a fin de introducir las medidas correctoras a que hubiere lugar. Y, a poder ser, siempre respondiendo a una lógica económicosocial, alejada de un absurdo economicismo y de un no menos absurdo colectivismo estatalista. Poderes públicos, asociaciones empresariales, organizaciones sindicales, partidos políticos y determinados movimientos sociales, deberian formar parte de un organismo regulador de la planificación democrática de la producción que, por otra parte, no sólo no se halla ilegalizada por leyes constitucionales, sino que algunas constituciones la reconocen y amparan legalmente. Bien es cierto, que con no mucha convicción, debido a la fuerte presión económica y política de partidos políticos de signo conservador y liberal que, febril y fervientemente, defienden a ultranza intereses privados y particulares, con escasa o de hecho nula preocupación por los intereses sociales y colectivos, limitándose a sugerir y proponer medidas de carácter asistencial. 
- Participación activa y autogestión. No se parte de la nada. Hay experiencias, unas no han prosperado, otras sí. Aunque la participación activa y la autogestión se refieren al cuádruple ámbito de lo económico, de lo político, de lo social y de lo cultural, ahora me voy a centrar en la actividad económica. Las empresas cooperativas agrícolas, industriales, de distribución, de servicios y de viviendas, nos ofrecen una buena y larga experiencia de lo que es la participación activa concretada en prácticas autogestivas o autogestionarias. En sus origenes surgieron con un objetivo: superar en el seno de la empresa la confrontación dialéctica entre capital y trabajo.

A tal objeto, entre otras cosas, crean cauces y se dotan de medios e instrumentos para democratizar la vida de la empresa en su doble dimensión, interior y exterior. Una adecuada y oportuna información, una consulta respecto a problemas y cuestiones más relevantes, una posibilidad para tomar parte en las decisiones y para ejercer el control de la evolución del proyecto en que se sustenta toda empresa cooperativa; $y$, todo ello, haciendo participes a todas las personas que la integran, constituye la esencia y fundamento de la participación activa real y autogestiva.

Esta práctica no es trasladable, en su totalidad, a la empresa privada capitalista ni a la empresa pública socializada, pero tampoco se puede negar la posibilidad de que, si no todo, al menos una parte, sea perfectamente aplicable y siempre en aras de alcanzar los objetivos económicos y sociales que estratégicamente se haya marcado la empresa; en la seguridad de que el grado de integración sería más alto y los conflictos, debidamente encauzados y negociados, lejos de tener efectos nocivos serian positivizados mediante el diálogo y el consenso. No faltan experiencias en tal sentido que hacen pensar que la democratización de la empresa y de la vida económica constituyen una utopía progresivamente alcanzable, que a nadie perjudica y a todos beneficia. La resistencia y oposición se halla en el poder tecnocrático, verticalista y dirigista, que, persiguiendo sólo el crecimiento económico y no el desarrollo social, es un obstáculo y un freno para el desarrollo económico y soçal. Todo un tema de meditación para fuerzas sociopolíticas organizadas, sean de derecha, de centro o de izquierda. Merece la pena introducir en la actividad económica prácticas de participa- 
ción activa y autogestión. No será posible a corto plazo, pero tal vez sí a medio y largo plazo. Sólo hace falta que en los equipos directivos haya voluntad política y tomar con seriedad y responsabilidad la cuestión.

- Mercado y competitividad. Dos realidades implicadas la una en la otra. Radicalmente necesarias y, por tanto, no se puede prescindir de ninguna de las dos, pero sabiendo que ambas son ambivalentes, es decir, que según se asuman y planteen, -absolutizándolas o relativizándolas-, se pueden derivar efectos tanto positivos como negativos. La praxis económica nos proporciona abundantes ejemplos en uno u otro sentido; los que, de modo racional amplian y dinamizan la actividad económico-social, y los que, irracionalmente, la frenan y desnaturalizan.

Si decimos que el mercado es un medio e instrumento básico y fundamental para la economía, no queremos decir que todo cuanto acontece en el mercado responda a una verdadera lógica económica. El mercado y la competividad no se pueden separar de lo que ocurre en la vida política, social y cultural. Aceptar esa separación es una incongruencia porque, deliberadamente, se ignora su influencia en el conjunto de la sociedad, algo muy común en quienes defendiendo al precio que sea intereses particulares, se olvidan del resto de la sociedad. Craso error, porque al tiempo que dificultan la solidaridad son causantes de insolidaridad. La ética no puede ni debe estar ausente de la actividad económica, una ética que sea radicalmente crítica y constructiva, buscando siempre el bienestar de la colectividad y, que, sin descuidar el bienestar individual, se aleje de la ética de corte individualista que domina en la sociedad.

Es importante no olvidar un presupuesto económico básico: la producción y el consumo son los dos polos de la economía. La distribución y la circulación actúan a la manera de mecanismos intermedios que se consideran imprescindibles. Hoy decimos, $-\mathrm{y}$ con razón-, que un proyecto de empresa comienza por el mercado, puesto que su objetivo estratégico es, -con independencia de que se enmarque en cualquiera de los sectores, dar respuesta a un segmento de necesidades descubiertas mediante la oportuna investigación del mercado. Pero otra cosa es que todo, desde la lógica exclusiva del beneficio, - sin previo discernimiento económico 
y social-, se traduzca a categorías mercantiles que, en vez de impulsar racionalmente el crecimiento y el desarrollo, lo distorsiona y desequilibra, hasta el punto de que la economia mundial se contempla casi en exclusiva bajo el prisma de cuotas de mercado. Así, y sólo así, -que es lo que está pasando-, se pervierte en su misma raíz el sentido auténtico de la economía. La responsabilidad del "neoliberalismo" es total en lo que a este aspecto se refiere. Con toda tranquilidad y, sin mayor profundización, leemos y hablamos acerca de la "guerra económica del siglo $X \mathrm{XI}^{\prime}$ ", que previsiblemente, no alterará la desigual relación centro-periferia.

En el fondo de lo que vengo diciendo, subyace una nueva concepción de la competitividad, propia de la nueva era tecnológica. Sobre este concepto no podemos hacer un juicio de valor univoco, afirmando que toda competividad es buena y necesaria. Como toda realidad económica, —depende del sistema socioeconómico en que opere y de su particular ideologia-, puede tener consecuencias para la sociedad claramente negativas. Suponiendo, $-y$ es mucho suponer-, que todo lo que se produce sea necesario, decimos que la competitividad existe realmente, cuando a un mismo tiempo, en un producto, se concitan positivamente estos cinco elementos: precio, calidad, oportunidad, diseño y diferencia. No hace falta ser muy lúcido y sagaz para caer en la cuenta de que la competividad así entendida, sólo pueden alcanzarla los paises productores de tecnología avanzada y las empresas transnacionales que dedican ingentes recursos a la investigación; las cuales, a la manera de enclaves económicos, se instalan donde creen converiente y en función de sus particulares intereses. No me puedo extender en el análisis de la actuación de estas gigantescas empresas por no alargar demasiado este trabajo, ya de por si extenso. Invito al lector a que, con la abundante información hoy existente, lo realice. No será una pérdida de tiempo. A la competitividad concebida en los términos señalados, tienen muy difícil acceso, - casi vetado, diría yo-, la pequeña y mediana empresa y los países subdesarrollados o en vías de desarrollo. Las primeras, caso de mantenerse, actuarán, de hecho, en régimen de subcontratación; y, los segundos, seguirán siendo, en la mayoría de los casos, suministradores de productos agrarios y de materias primas, a los precios predeterminados por los países desarrollados. Es la conse- 
cuencia, -muy dificil de atenuar-, de la lógica de la internacionalización del capital y de los mercados. Es la "ley de la jungla" la que viene regulando las relaciones en este inmenso escenario en que se ha convertido el mercado. Los fuertes sobreviven, los débiles son absorbidos o inmolados, si llega el caso. Me pregunto, ¿el "neoliberalismo", consolidado y difundido, no nos estará conduciendo a una especie de "holocausto económico-social", en el que, masivamente, las víctimas seguirán siendo los pobres y desheredados de la tierra? Observemos nuestro derredor y veamos qué consecuencias se pueden extraer.

- Libertades civico-politicas. Considero que las libertades cívicopolíticas constituyen una importante aportación del liberalismo político propio de los Estados de Derecho Liberal, en congruencia con las exigencias del liberalismo económico (capitalismo). No se explican el uno sin el otro. Defender la libertad de empresa, de mercado y de contratación, únicamente tiene sentido si, simultáneamente, se reconocen, amparan y defienden las libertades de opinión, expresión, reunión, asociación y manifestación. Estas libertades no pueden ser puestas en cuestión, ni menos negadas, pues si asi fuera, se incurriria en prácticas antidemocráticas. De ahi, a caer en actitudes autoritarias y dictatoriales hay un sólo paso. La experiencia pone de manifiesto que casi siempre se da. Los riesgos que ello comporta son ya conocidos. No insisto.

- El ejercicio de las libertades es consustancial a la democracia, ya que ésta no puede existir sin aquéllas. Pero queda, a la manera de asignatura pendiente, el paso de la libertad formal a la libertad real. Ya desde el siglo pasado se viene insistiendo en el hecho de que, por declarar constitucionalmente la "igualdad de todos los ciudadanos ante la ley", dicha igualdad legal no equivale a igualdad real, pues la desigualdad económica y social continúa constatándose sociológicamente. Con la excepción de un reducido número de países altamente desarrollados, las diferencias se han ampliado en vez de reducirse. Por éso, no es cierto que el ejercicio de las citadas libertades sea similar para todos. $Y$ esta realidad, si bien legal y legitimamente se viene admitiendo, desde una perspectiva ético-política debe someterse a severa crítica, ya que lo que se halla en juego es la dignidad del ser humano, de toda persona, sin excepción. 
- Crisis de la sociedad civil. En la actualidad, con ocasión de la crisis que atraviesa la democracia en el mundo occidental, se ha suscitado la necesidad de plantearse el fortalecimiento de la sociedad civil. Ya en el año 1987, S. Giner, en referencia a los "Avatares de la sociedad civil", dice que ésta "puede definirse como aquella esfera históricamente constituida de derechos individuales, libertades y asociaciones voluntarias cuya autonomia y competición mutua en la persecución de sus intereses, e instituciones privadas quedan garantizadas por una institución pública, llamada Estado, la cual se abstiene de intervenir políticamente en la vida interna de dicho ámbito de actividades humanas". No es la única definición, pero nos ayuda a proseguir con cierta coherencia nuestra reflexión.

Para nadie es un secreto que el individualismo es el soporte filosófico del liberalismo y del "neoliberalismo". Esto significa que el individuo ostenta la voluntad soberana y es principio de la sociedad civil. No obstante, en el ámbito de las asociaciones voluntarias esa autonomía adquiere formas monopólicas y oligopólicas; $y$, además aflora un exceso de privacidad que se aleja y hasta se opone a lo público. El Estado corre el grave riesgo de perder su verdadero sentido político y consecuentemente se debilita la democracia. En buena medida, se convierte al mercado en principio organizativo de la sociedad civil; y, de tal hecho, -libertad de transacciones y de competitividad-, adquieren gran fuerza y capacidad de presión política las conocidas tendencias económicas monopolísticas y oligopolísticas que pronto han desembocado en oligarquias políticas. Al tiempo que se habla de pluralismo, como marco político que favorece la convivencia, el acceso al poder y su consiguiente ejercicio se produce de forma desigual y asimétrica dada la división en clases sociales que en la sociedad seguimos percibiendo de forma cada vez más acentuada. En una sociedad así, resulta muy difícil y hasta prácticamente imposible, plantear acciones que comporten avances en materia de justicia social.

En una sociedad insolidaria, en la que lo público y lo privado aparecen como realidades divergentes y en confrontación en lugar de ser convergentes y complementarias, el autor citado destaca la aparición de fenómenos como los siguientes: - corporativismo, o defensa de intereses profesionales y gremiales, que desplazan y 
hasta anulan otras organizaciones de la vida social; -expansión estatal, concretada en un denominado "estado benefactor" con funciones asistenciales que amplian en exceso la burocracia administrativa; -congestión institucional, que es consecuencia de la burocracia anterior a la que se suma la que genera el corporativismo; -tecnoculturn, que aparece vinculada a la gerencia corporativa propia de la incorporación masiva de innovaciones tecnológicas y todavía no se puede ver claramente su compatibilidad con la sociedad civil ya que, en sí misma, constituye un freno para su desarrollo.

Precísamente, y como respuesta a lo que acabo de exponer, en un reciente seminario de profesionales jóvenes promovido por "Cristianisme i Justicia" (Barcelona), se formulan las siguientes propuestas concretas: a) Potenciar los grupos, asociaciones y movimientos de toda clase ya existentes, nacidos en perspectiva solidaria (no corporativa), así como crear nuevos grupos; b) revisión, por parte de los partidos políticos, de su posición recelosa ante los grupos y movimientos sociales; c) puesta en práctica del principio de subsidiariedad; d) redefinir el sentido del servicio público; e) tener en cuenta que ningún reconocimiento de derechos puede sustituir la falta de estructura de acogida adecuadas; f estructura democrática para todos los grupos; g) apertura de los medios de comunicación a los diferentes agentes sociales, en especial los medios de comunicación públicos.

- Ante la realidad de unn sociedad dividida en clases. El hecho de las clases sociales aparece como realidad objetiva tan incuestionable como controvertida en lo que a su teorización se refiere, desde comienzos del siglo XDX hasta el momento actual. En torno al mismo se han ido perfilando tres posiciones claramente diferenciadas, a saber: una, conservadora, que reconoce la existencia de las clases sociales y la asume en una visión interclasista de la sociedad, porque contribuye a la organización social; otra, reformista, difiere de la anterior porque admite la existencia de intereses contrapuestos entre las clases sociales que, a su vez son causa de conflictos que, superados y encauzados mediante la negociación y el consenso, obligan a la realización de determinadas reformas que pueden contribuir a transformar lentamente la estructura social; $y$, una tercera, revolucionaria, que se aleja de las dos anteriores, puesto que 
entiende que las clases sociales no sólo se hallan en conflicto, sino que se percibe un antagonismo expresado en términos de lucha de clases que debe ser agudizado hasta sus últimas consecuencias, convirtiéndose asi en método para transformar la estructura social.

En la actualidad, sin negar la relativa presencia activa de las posiciones conservadora y revolucionaria, en los países más desarrollados e incluso en algunos que se hallan en vías de desarrollo, -en la medida que se ensancha el espectro social de las clases medias-, la tendencia se decanta por la segunda posición calificada como reformista, con el convencimiento de que determinadas reformas jurídicas, económicas, políticas, sociales y cultural-educativas, por situarse en el plano estructural, tienen la posibilidad de modificar paulatinamente la estructura social. No es, por tanto, el momento de revoluciones armadas. Si el de reformas estructurales. Es decir, que los cambios posibles y deseables pueden lograrse mediante una presión económica, política y social, en lugar de recurrir a la violencia.

Pero, en todo caso, sí conviene tener presente que, pese a los intentos reformistas, -unos concluidos con relativo éxito y otros con relativo fracaso-, lo cierto es que las desigualdades que sociológica y objetivamente se pueden constatar, en vez de reducirse se han ido consolidando y aumentando, cosa que no puede pasar desapercibida y creer que se superan con la abundante verborréa social a la que estamos acostumbrados, propia de quienes sugieren leves cambios para que las cosas sigan igual. La superación del "socialismo real" por parte del "capitalismo real" no obliga, necesariamente, a dar por concluida la existencia de clases sociales y la confrontación estructural de intereses entre las mismas. Hasta podemos observar, que el "consumismo", el "productitivismo" y el "competitivismo" de nuestro tiempo, concretados en la trama interna del "neoliberalismo", ha hecho que dicha confrontación-, si bien, se atenúa en los países más desarrollados-, se acentúa en determinadas áreas geográficas y entre determinados países, adquiriendo una dimensión, en cierta medida, de carácter internacional. La definición de los nuevos escenarios económicos para el siglo XXI, - caso de no implementarse medidas efectivamente correctoras de desequilibrios económico-sociales-, nos puede depa- 
rar sorpresas muy poco agradables que todavía no podemos prever. Es una especie de "alerta para navegantes", para los que llevan el "timón de la nave neoliberal". ¿Dispondrán de "brüjula" para enderezar el "rumbo"? Sinceramente lo dudo, pues en vez de realizar análisis profundos y estructurales, siguen empeñados cerrilmente en sus planteamientos economicistas y economicidas, limitándose a mirar de reojo y por encima del hombro a grupos sociales y paises inmersos en situaciones de pobreza extrema y de miseria, de las que, ni mucho menos, se hallan exentos de responsabilidad.

- Democracia participntiva. Con mucha frecuencia se repite y oímos que la democracia no se puede limitar al ejercicio del derecho de voto. La realidad, en cambio, pone de manifiesto que en muchas ocasiones se reduce a esta práctica. No quiero restar importancia a este derecho básico, pues sin sufragio universal no hay democracia, quiero subrayar que su simple ejercicio no es la democracia. Tienen razón quienes opinan que la democracia actual es lo más parecido a una "tecnocracia" en la que los políticos elegidos tardan bien poco en alejarse de quienes los eligieron. Es por esto, por lo que los electores no pueden ni deben ceder su capacidad de decisión sólo en los poderes públicos.

La cuestión de fondo se sitúa en la misma lógica del poder que, nos agrade o no, adquiere una tonalidad jerárquica y verticalista descendente, dirigentes-dirigidos -, descuidando la perspectiva horizontal y vertical ascendente que, de suyo, obliga a una descentralización en los momentos de tomar decisiones que afectan a toda la comunidad. Esta descentralización hay que contemplarla, como exigencia para una solución adecuada de los problemas actuales, diversos y complejos, tanto si son económicos, como políticos, sociales y culturales, todos éllos relacionados entre sí. De forma que la consecución de lo que llamamos bien común o bienestar general no quede sólo a expensas de lo que el Estado promueva y realice, sino que su acción sea complementada por iniciativas organizadas de los ciudadanos. Se trata, en último término de recuperar parcelas de soberania popular, haciendo posible el desarrollo de la vida asociativa como base para la vertebración de la sociedad civil en una línea solidaria, alejada de las prácticas corporativistas. 
De lo que se trata, es de que la democracia hoy denominada representativa lo sea de verdad y permita el paso a una democracia participativa, fundamentada en un amplio tejido asociativo que, a su vez, haga posible que los ciudadanos abandonemos el rol negativo de simples espectadores y nos convirtamos en protagonistas responsables y comprometidos. Y, esto no será posible si, en tanto ciudadanos, - depositarios de la soberanía popular-, no somos convenientemente informados y oportunamente consultados, ni tampoco participamos directamente o por representación en la toma de decisiones y en el control social que todo proyecto global requiere. La democracia liberal actual, en todo el ámbito occidental, dista todavía mucho de responder a las exigencias de una democracia real. Yo, al menos, no conozco ningún país, en que dicha democracia real y participativa se haya dado. Vale la pena analizar las causas y consecuencias.

- Intervención del Estado. También se trata de una cuestión polémica y controvertida, de verdadera actualidad. El Estado colectivista ha fracasado y la larga experiencia de Estados de Derecho liberal no se puede considerar satisfactoria debido al exceso de burocracia administrativa y a los casos tan repetidos de corrupción por parte de personas que han ocupado puestos de gran responsabilidad en los distintos planos de la esfera pública, lo que hace más urgente el desarrollo de la sociedad civil que, desde actitudes éticas y criticas, puede ayudar a superar dichas actuaciones inmorales; pero, no sólo aquéllas en las que se pueda haber incurrido desde el Estado, sino también de otras actuaciones no menos corruptas e inmorales en que se incurre en la economía de mercado, constituyendo a éste en plataforma de las operaciones más degradantes y antiéticas para una política económica racional y socialmente planteada.

Me parece inapropiada la crítica tendenciosa, interesada y no bien fundamentada que desde posiciones neoliberales se hace del Estado. Tan inadecuado e improcedente resulta un exceso de Estado como un exceso de privatización o de mercado que pretende expresarlo todo o casi todo en base a categorías mercantiles. Aunque por diferentes razones, $\tan$ inconveniente y nociva es una estatificación de desproporcionadas dimensiones como una exagerada exaltación del mercado que sólo considera la respuesta a ne- 
cesidades sociales y colectivas cuando ve en ellas una oportunidad de negocio, quedando excluidos de cobertura los grupos económicamente débiles, ya que quedarán reducidos a la condición de "demanda insolvente". Hay un evidente trasfondo de injusticia que por razones éticas no puede ni debe pasar desapercibido.

Por otra parte, desde comienzos del siglo pasado y hasta el momento actual, parece bastante evidente que el Estado ha sido instrumentalizado por parte de un sistema socio económico capitalista liberal e individualista, que hoy se autodefine como "neoliberal". Muy resumidamente dicha instrumentalización ha pasado por las siguientes fases: 1a) El sistema obliga a que el Estado se inhiba en todo lo relativo a la actividad económica y social; 2a) El Estado, después de promulgarse las leyes que regulan la actividad económica, es el encargado de vigilar su cumplimiento y de imponer las sanciones correspondientes a quienes incumplen sus compromisos y transgreden las normas establecidas; 3a) Del Estado se reclama una respuesta para las necesidades colectivas (educación, sanidad, orden público, seguridad social) que no resultan remuneradoras para la iniciativa privada, y, a tal fin, por vía fiscal -directa e indirecta-, el sistema proporciona los recursos necesarios que, casi siempre, son insuficientes; 4a) Según momentos y situaciones, se ve conveniente que el Estado, directa e indirectamente, $\rightarrow$ a través de empresas públicas-, intervenga en sectores básicos que reclaman grandes inversiones e implican altos riesgos que la iniciativa privada no está dispuesta a asumir; 5a) Con el paso del tiempo el Estado aparece como agente o sujeto público de la vida económica, ya que simultáneamente es importante productor y consumidor, llegando a suscribir contratos de gran envergadura con la empresa privada; 6a) A partir de la segunda mitad del presente siglo, cuando se definen las economías mixtas o de doble sector - público y privado-, la misión del Estado es la de dirigir la política económica, a cuyo fin elabora el cuadro macroeconómico y realiza un seguimiento sectorial, tratando de administrar la crisis económica y de corregir desequilibrios interiores y exteriores; 7a) A partir de 1980, con el auge relativo del pensamiento neoliberal, que ha implementado duras políticas de ajuste económico, cuyos efectos negativos - léase, altos costos sociales-, han sido soportados por los grupos peor situados y más 
desfavorecidos, la tendencia es a privatizar las actividades económicas y sociales realizadas por el Estado y a reducir la magnitud de éste para ampliar la tasa de beneficio del sector privado.

Se revela así, no la incapacidad del Estado, sino la del sistema, para dar una respuesta suficiente y universalizada a las necesidades colectivas, como son la sanidad, la educación, la seguridad social, la vivienda y la infraestructura adecuada para agilizar el desarrollo económico y social. Las consecuencias no se hacen esperar, pues no es casualidad el hecho de que las desigualdades entre individuos, grupos, clases y países, al no ser acometidas en su raíz, siguen incrementándose.

- Orden intemacional. Hay análisis y opiniones "para todos los gustos". Se habla, al mismo tiempo, de "nuevo orden internacional" y de "nuevo desorden internacional". Según sea el ángulo focal en que nos situemos y los datos que manejemos, nos descubriremos en una u otra posición. Por mi parte, creyéndome realista -aunque sin abandonarme a la desesperanza-, considero que el desorden económico, político, militar y social en que nos encontramos actualmente es como para elaborar una "antologia del disparate". Reconozco, en cualquier caso, que voluntad, gestos y determinadas acciones de carácter gubernamental y no gubernamental que insistentemente se plantean, contribuyen a paliar una situación que reune todos los elementos para ser explosiva, demostrando que seguimos siendo el pueblo, los pueblos, de cerviz granítica, dirigidos con escasa sabiduria.

A costa de lo que sea, caiga quien caiga, -los hechos, en cualquier parte del planeta, son estremecedores-, el afán de protagonismo económico, político, cultural, ideológico, militar e informativo, tiene como objetivo alcanzar el máximo posible de hegemonía. Los acuerdos "entre los grandes" que nunca llegamos a conocer en su entramado interno de intereses, son reflejo claro de pretensiones hegemónicas, como también lo es el "club" de los diez países más ricos. Cuando éstos se reúnen, tratan de valorar la situación a nivel planetario, atribuyendo, como es lógico, prioridad a sus propios intereses $u$ otorgando en ciertas ocasiones preferencia a los intereses de otros países siempre y cuando ésto favorezca su beneficio particular. Es un contrasentido, por tanto, pensar que unos países ayuden a otros sin esperar nada a cambio a corto, 
medio y largo plazo. Para nadie es un secreto la distinta capacidad de influencia y de presión que los países tienen en la Organización de las Naciones Unidas.

Al desaparecer la polarización en dos bloques, la estructura económica internacional se encamina hacia la división de tres bloques diferentes, pero interrelacionados y complementarios: América, con EE. UU. como cabeza; Europa, con la U.E. en marcha, no sin serias dificultades y con Alemania como pais de economía más fuerte; y el Este y Sudeste asiático, como área de influencia para la economía de Japón, con sus reconocidas posibilidades en tecnología avanzada. En un futuro económico mundial, en el que la internacionalización de mercados es un hecho, el librecambio y el proteccionismo representarán el soporte ideológico de las relaciones económicas, comerciales y financieras internacionales. Los países subdesarrollados o en vias de desarrollo, de no corregirse la trayectoria, -cosa poco probable-, irán pasando de una situación de "dependencia" a otra de "prescindencia", al tiempo que las grandes empresas transnacionales aprovechan la tendencia privatizadora para ampliar sus enclaves económicos, con lo que la soberanía nacional quedará reducida casi a pura expresión retórica.

En lo concemiente al orden y equilibrio internacional en el cuádruple plano económico, político, social y cultural, el futuro se halla cargado de tensiones, de incertidumbre e inestabilidad. ¿Será una quimera o un espejismo el nuevo orden internacional? Pienso que no tiene por qué ser necesaria y absolutamente asi, si se hace caso de las numerosas voces ético-criticas que intentan hacerse escuchar en todos los continentes. El destino de la humanidad no puede dejarse en manos del indisimulado dogmatismo y fanatismo neoliberal que, hasta el momento, no da señales de aprender las lecciones de la historia ni de querer entender los mensajes que pueden leerse en informe sociológicos (económicos, políticos y sociales); ofrecen una resistencia desorbitada a cualquier análisis critico que obligue a revisar sus posicionamientos y actuaciones, $y$, en consecuencia, la posibilidad de que sus más fervientes defensores realicen con rigor su propia autocrítica, se halla todavía muy lejos. ¿Será tan difícil plantearse y hacerse preguntas radicales en torno al hombre en el mundo, las carencias de todo tipo para los 
dos tercios de la humanidad, las dificultades para frenar el desempleo y las emigraciones, el deterioro ambiental que el sistema industrial continúa produciendo, el productivismo empeñado en fabricar cosas innecesarias, etc.? $O$ es que, ¿vamos a permanecer impasibles ante el riesgo de nuevas y destructivas confrontaciones? ¿Consideramos humana y éticamente aceptable que las medidas que con más insistencia se proponen vayan encaminadas a contener el crecimiento demográfico impidiendo el nacimiento de nuevos seres? ¿Es que vamos a seguir mirando a los ojos de un niño o de una riña sin sentir vergüenza? Nuestra sensibilidad ante la injusticia y el dolor humano se halla seriamente cuestionada ¿Qué haremos?

- El impacto de las nuevas teciologíns. Inmediatamente después de la segunda guerra mundial, la sociedad, el mundo, ha entrado en la segunda revolución industrial, definida ya como era de la microelectrónica, aplicando las nuevas tecnologías a usos civiles y militares, con efectos desestructurantes en las cuatro variables económica, política, social e ideológica-cultural-, que vertebran la sociedad. De manera muy sucinta, destacaré los aspectos que pueden ser considerados como más relevantes en cada una de ellas, sin perjuicio de un análisis exhaustivo que conviene realizar. Son los siguientes:

- En la actividnd económica: -disminuyen los costos de producción, aumenta la productividad y la producción; -de la competitividad se ha pasado al competitivismo, de la producción al productivismo y de una pretendida racionalidad al irracionalismo; -la tecnologia se autonomiza y genera servidumbres; - el mercado se internacionaliza y el planeta se reduce a cuotas de mercado, o áreas de influencia; $\rightarrow$ se hace patente el predominio y la prepotencia de grupos tecnocráticos; - la obsolescencia es objeto de planificación y la necesaria acumulación de capital es causa estructural de la crisis; -el desequilibrio sectorial continúa siendo realidad; - no se equivocan quienes afirman que la crisis también es de superproducción; - se informatizan los procesos, productivos, administrativos, organizativos y de gestión, convirtiéndose la información en primera materia; - pequeñas y medianas empresas, para subsistir, pasan a ser subcontratantes; -al tiempo que se insiste en el librecambio, abundan las prácticas proteccionistas. 
- En el ámbito político: -la democracia liberal, con un poder ejecutivo en manos de gobiernos muy tecnocratizados, difícilmente podrá desembocar en una democracia representativa, social y participativa; - las elecciones registran elevados porcentajes de abstención, expresión fidedigna de la indiferencia política de grandes contingentes de población censada electoralmente; -al tiempo que se reconoce el pluralismo, la vida asociativa se halla escasamente desarrollada; -el poder, sin salir de su lógica tradicional, continúa basado en la riqueza, los intereses de grupo, la investigación, la tecnologia, la energía, la competitividad y la capacidad disuasiva de la fuerza militar; $\longrightarrow$ el profesionalismo politico, -hay quienes lo denominan elitismo-, es una permanente tentación para caer en prácticas corruptivas que alejan aún más a las bases sociales de los partidos; el pragmatismo político es un serio obstáculo para recuperar la utopía.

- En el plano social: -las desigualdades no sólo no se reducen sino que aumentan, tendiendo a consolidarse la sociedad dual o de los tres tercios; - aumentan las tasas de desempleo, que, salvo excepciones, van del $5 \%-15 \%$ en los paises desarrollados, al $30 \%-50 \%$ en los países subdesarrollados; este alto desempleo es un azote para la juventud, para los trabajadores adultos con contratos de trabajo en suspensión o rescindidos y para el colectivo femenino que ve acentuarse su discriminación; - la clase trabajadora, desestructurada, observa cómo ha disminuído la afiliación sindical y su capacidad de presión en la negociación colectiva; $\rightarrow$ se dice que se está pasando de la civilización del trabajo a la civilización del ocio (trabajo-oçupación), pero este fenómeno se halla muy lejos de interiorizarse; - la economía o sociedad del bienestar se halla en franca crisis, como consecuencia de la crisis económica mundial; - un cierto corporativismo se ha hecho presente en la clase trabajadora, al tiempo que son bastantes los trabajadores cuya capacitación no se ajusta a las exigencias de las nuevas tecnologías y encuentran serias dificultades para actualizar su preparación técnica.

- En el plano ideológico-cultural: - la postmodernidad que desde hace décadas se refleja en el arte, se asienta cada vez más en la razón, la investigación y la ciencia; -se infravalora el sentido de lo utópico y de lo transcendente, lo cual es sintoma de deshu- 
manización; -con un esfuerzo digno de mejor causa se insiste torpemente en el fin de las ideologias; - la cultura consumista y tecnológica desencadena un proceso de homogenización cultural, en detrimento de las tradiciones y culturas de los pueblos; -la sociedad, en general, es acritica, y la universidad en la medida que se pragmatiza excesivamente va cediendo en su misión como instancia ética y crítica; -la escasa aplicación del análisis estructural hace que la superficialidad sea la moneda más corriente; -del diálogo y la comunicación se va pasando a la incomunicación y al aislamiento; - la ideología neoliberal e individualista, ampliamente extendida y fuertemente interiorizada, es causa próxima y remota de la manifiesta insolidaridad que podemos advertir en todos los planos.

- Formación ética y educación crítica: Que contribuyan a promover solidaridad, ya que en la sociedad actual es el déficit más significativo. Una formación ética y una educación crítica y autocrítica que cristalicen en una mentalidad individual y colectiva, es decir, profundamente enraizada en la conciencia personal-, que haga posible una modificación de actitudes y comportamientos, para que aquéllas y éstos se inscriban en un proceso humanizador y se alejen de las prácticas deshumanizantes que con tanta frecuencia nos ofrecen los medios de comunicación social. Que podamos realmente afirmar, -porque así lo constatamos-, que las personas, de verdad nos. mostremos como seres pensantes que somos, y que hagamos que no se cumpla ese "pronóstico" para el próximo siglo que augura para entonces la división de la humanidad en dos grupos: uno, minoritario, integrado por los que piensan; y otro, mayoritario, masificado; del que formarán parte los que no piensan. La ética y la crítica -ésta no superficial sino estructural-, alejarán del horizonte ese negro presagio.

La ética y la educación crítica se constituyen así en exigencia básica y fundamental para garantizar la supervivencia de los diversos colectivos humanos, su cohesión y la convivencia pacifica. Hará posible encarrilar el futuro de la sociedad mundial por senderos de solidaridad, al tiempo que se reduce la violencia estructural y se avanza en respeto a la pluralidad cultural. El reconocimiento y defensa de los derechos humanos por parte de todos los países, la promulgación de normas y la dotación de medios para 
que se garantice su cumplimiento, son pasos efectivos que ya se están dando, aunque todavía quede mucho por hacer. La tolerancia, el diálogo, la negociación y el acuerdo, deben sustituir a la intolerancia, a la incomunicación, a la confrontación y al disenso permanente. Grande y muy digna tarea, pues, la que es preciso realizar para que la ética -económica, politica, social-, constituida en instancia crítica y autocrítica adquiera carta de naturaleza y forme parte, como contenido esencial, no sólo de los planes educativos sino de la actividad profesional en cualquier rama de actividad. Una critica, en definitiva, que ilumine e inspire la acción humana, toda acción humana. Si la ética no ocupa un lugar preferente, el dislate continuará haciéndose presente y el futuro será muy poco alentador.

$Y$, para concluir, diré que, si mi opción - la opción que propongo-, el "socialismo democrático", sostenida por muchos y en distintos lugares, puede y debe ser un camino y un proceso que se consolide lentamente y a largo plazo; ello, no significa que sea el único proyecto para la liberación-emancipación de la sociedad actual y menos pretenda presentarse como el futuro de la humanidad. La necesidad de recuperar el discurso utópico no ha de orientarse en una sola dirección, pues sería caer en el mismo error del neoliberalismo. Tampoco es monopolio del marxismo ni de la izquierda, habida cuenta de la existencia de una izquierda no marxista. Tampoco descartar lo que hay de positivo en el planteamiento liberal y en el planteamiento marxista, que siguen arraigados en importantes contingentes sociales y presentes en núcleos intelectuales. No se pueden ignorar las clases sociales y el conflicto, unas veces latente y otras manifiesto, entre las mismas, pero no es ya el momento para proyectos excesivamente clasistas y obreristas, debido a los cambios sociológicos experimentados por la clase trabajadora.

Sí es el momento de aunar esfuerzos por parte de organizaciones sociales y políticas con tradición de izquierdas, de centro-izquierda y hasta de centro-derecha. Respetando la identidad ideológica de cada opción, puede ser posible hacer propuestas más o menos coincidentes, cuya puesta en práctica implique avanzar en una línea de transformaciones sociales, correctoras y reductoras de los desequilibrios económicos y sociales que hoy nos abruman, 
teniendo bien claro que las distintas políticas que se implementen deben favorecer a los grupos sociales más débiles y más pobres material y culturalmente. Pero no como una práctica caritativa y asistencial, sino con clara conciencia de que se les restituye lo que se les debe porque los ricos y poderosos de la tierra han acumulado exceso de riqueza y de poder. No podemos olvidar que el $20 \%$ de la población mundial se adjudica y utiliza el $80 \%$ de los recursos existentes, mientras otro $20 \%$ de la misma población sólo dispone del $1.5 \%$ de dichos recursos. Es muy difícil que la derecha conservadora y neoconservadora, recalcitrante y montaraz, acantonada en las estructuras de poder económico-político-militar, se sume a un proceso que, si utópicamente aspira a desembocar en un "socialismo democrático", lo importante es que sea de signo humanista y humanizador, ya que, lo que se persigue es la promoción humana, la libertad para todos, la democracia real-participativa y social- y explorar caminos de solidaridad y de paz. $Y$ esto tiene que ver muy poco o nada con el marxismo-leninismo propio de otras épocas y con el neoliberalismo que nos invade y atenaza en el momento actual. Cuanto antes salgamos de esta especie de movimiento pendular, será mejor para todos. La humanidad, -las generaciones futuras-, lo agradecerán, y a los pobres y oprimidos de la tierra, por fin, se les hará justicia.

Pero, no nos podemos engañar, hoy el "neoliberalismo", -valga la metáfora marina-, se halla en la "cresta de la ola" y el "socialismo democrático humanista" es la "ola de fondo" que tardará en hacerse notar. Por éso, todos, con independencia de la ideologia que creamos encarnar y sin excepción, tenemos éticamente la responsabilidad de hacer lo posible y de hacer posible lo imposible para que esa "ola de fondo" no se convierta en "maremoto", evitando que páginas tristes de la historia se repitan. Y quienes social e intelectualmente nos sentimos comprometidos con el necesario cambio social, tenemos el deber de seguir profundizando en el análisis que he intentado esbozar. 